\title{
The Transmission of Multigenerational Educational Inequality
}

Jeremy E. Fiel

The University of Arizona

Running head: MULTIGENERATIONAL EDUCATIONAL INEQUALITY

Key words: education, inequality/stratification

Word Count (manuscript, references, endnotes): 9,430

6 Tables (including appendices), 3 Figures

Supplementary File attached

*Thanks to Christina Diaz and Gary Solon for helpful feedback. Direct correspondence to: Jeremy E. Fiel, University of Arizona, Department of Sociology, Social Science Bldg, Rm 433, P.O. Box 210027, Tucson, AZ 85721-0027; e-mail: jfiel@email.arizona.edu; phone: 520-6218744. 


\begin{abstract}
This study explores the transmission of educational inequality across three generations in the U.S. It addresses two common problems in analyses of multigenerational inequality: omitted mechanisms of indirect transmissions through grandparents' early influences on parents, and theoretically problematic tests of direct effects based on non-zero residual grandparent-child associations. The first problem leads to upwardly biased direct effect estimates; analyses that control for parents' attributes and experiences during their own childhood eliminate most grandparent-child educational associations. Conversely, the second problem can obscure direct effects. This study avoids inferring direct effects from residual grandparent-child associations by assessing the explanatory power of measured child attributes that constitute likely mechanisms of direct effects. It finds little evidence of direct effects overall, although there is some indication of direct effects on bachelor's degree attainment among those with the most educated grandparents. The findings also speak to potential mechanisms of direct and indirect educational transmissions.
\end{abstract}


Is a two-generation parent-child model of intergenerational stratification adequate, or do the social origins relevant to one's attainment have deeper roots? Put another way, how much do the status and resources of grandparents or more distant ancestors matter for one's life chances, and how do they matter? Though these are old questions (Hodge 1966), empirical investigations are relatively new (Mare 2014; Pfeffer 2014; Solon 2014). I advance the growing research on multigenerational inequality by probing the transmission of educational status across three generations in the U.S., making two contributions. First, I provide new evidence on whether grandparental status affects children's attainment directly; not directly in the sense that grandparental status has any unmediated influence on children's attainment, but in the sense that some grandparental status effects are unmediated by early influences on parents, which constitute indirect effects. Second, I provide new evidence on how advantage and disadvantage are transmitted across multiple generations, both indirectly and directly.

To do so, I incorporate measures of key mediating constructs in the parent and child generations, including family processes and childrearing practices (Lareau 2003; McLanahan and Percheski 2008), early skill development (Farkas 2003; Heckman 2006), and socioeconomic goal formation (Sewell, Haller, and Portes 1969). These measures are a strength of the Child and Young Adult Cohorts of the National Longitudinal Survey of Youth 1979 (NLSCYA), which has followed contemporary young adults since birth and followed their parents since adolescence. By adding measures of parents' early experiences and attributes to the parent socioeconomic attainment measures typically used in this research (Chan and Boliver 2013; Hertel and GrohSamberg 2014; Warren and Hauser 1997), I account for the possibility that grandparental status influences parents' upbringing in ways that trickle down to children irrespective of parents' attainment. Grandparents' status may shape the early development of parents' values and skills, 
for instance, which then influence the way parents raise their own children. Analyses limited to parent attainment measures may misattribute such indirect transmissions to direct effects.

I also incorporate measures of children's early traits and experiences to capture direct multigenerational effects, a new approach with some advantages. One is that it increases the face validity of direct effect estimates: rather than attributing residual grandparent-child educational associations not explained by parent characteristics to direct effects, it tests whether measured child characteristics featured in theories of direct transmissions can explain those associations. Another is that unlike residual-based methods, this approach can reveal direct effects operating through child characteristics even when conditional grandparent-child educational associations are negative, as some theories predict (Becker and Tomes 1979). By implicitly comparing residual associations to zero, typical methods may actually obscure direct effects.

Incorporating these additional parent and child measures enables another contribution: to decompose indirect and direct multigenerational transmissions into portions explained by the aforementioned theoretical constructs. Though this decomposition is descriptive, it sheds some light on the potential importance of different avenues of multigenerational transmissions. I also allow the effects of mediating constructs to differ by grandparental education, permitting differences in the transmission of educational inequality among those from the most advantaged and the most disadvantaged backgrounds.

\section{Theories of Multigenerational Stratification}

\section{A Markov Process}

Until recently, most scholars theorized intergenerational stratification as a Markov process: the transmission of socioeconomic attainment within family dynasties across three or more generations - hereafter called multigenerational effects - is indirect via a chain of parent- 
child relations, with no direct or lagged effects of grandparents' or other ancestors' attributes. In the Markov account, indirect multigenerational effects occur via a series of natural or intentional parent-child transmissions of various characteristics, resources, and experiences: genetically transmitted skills and personality attributes (Nielsen 2006; Plomin, Owen, and McGuffin 1994); culturally transmitted norms, values, and dispositions (Bourdieu and Passeron 1977; Farkas 2003; Lareau 2003); social psychological influences on children's goals and orientations (Sewell, Haller, and Ohlendorf 1970; Sewell, Haller, and Portes 1969); human capital investments intended to promote children's attainment (Becker and Tomes 1979; Behrman, Pollak, and Taubman 1995); resources and opportunities accessed through social networks (Bourdieu 1986; Coleman 1988); and financial or other material bequests (Mulligan 1997).

Such transmissions create parent-child similarities in socioeconomic outcomes, which (indirectly) link multiple generations. Multigenerational similarities are thought to weaken across generations due to imperfections and costs associated with various transmissions and the role of luck in the attainment process (Becker and Tomes 1979; Bourdieu 1986). This two-generation framework has supported decades of stratification research, and it may suffice even if the Markov account does not strictly hold. If parent-child transmissions are powerful enough, the two-generation model may capture the most important aspects of intergenerational inequality, even if grandparents or other ancestors do directly matter (Hodge 1966).

\section{Direct Multigenerational Effects}

Recent research questions the Markov approach, pushing stratification theories to consider the direct influences grandparents' status may have on children's life chances (Solon 2014). From an evolutionary perspective, grandparents have a stake in promoting the survival and reproductive fitness of their children and grandchildren, because this increases the 
proliferation of their own genes (Coall and Hertwig 2010). From a sociological and economic perspective, grandparents have a stake in the socioeconomic success of their grandchildren just as they do for their children, either because they are altruistic or because they expect investments to be returned in the form of support in old age (Friedman, Hechter, and Kreager 2008).

Direct effects described in prior work often involve grandparent-child interactions and bequests that circumvent parents: grandparents can promote children's attainment by being role models and stewards of family norms and values, replacing parents in childrearing, directly transmitting wealth to children, or conferring legacy or reputational effects on children (Bengtson 2001; Hallsten 2014; Hogan, Eggebeen, and Clogg 1993; Møllegaard and Jæger 2015; Mulligan 1997; Zeng and Xie 2014). In other cases, the direct-indirect distinction is murky. Many grandparental efforts to influence children's lives are mediated by parents given the primacy of parental authority (Chan and Elder 2000; Cherlin and Furstenberg 1986; Kivett 1991). Grandparents might alter parents' childrearing strategies by giving advice, for instance, or they might give parents money to purchase experiences or opportunities for children. Should such influences count as direct effects?

This issue is yet to be resolved, and it is beyond the scope of this paper to do so. My working assumption here is that such influences are direct. Specifically, I distinguish indirect effects as grandparental influences on parents during parents' upbringing that are not intended to influence children's life chances. Direct effects are grandparental influences during children's upbringing that influence children's life chances, whether intentional or not, and whether mediated by parent action or not. This is not a comprehensive distinction, and it leaves some ambiguities; I will discuss them as they arise in my analyses. The same distinction is implicit in studies that use residual grandparent-child associations to test direct effects. 
In any event, direct grandparental influences depend on many factors. Grandparents may take on a more important role when parents are absent or compromised due to marital disruption, incarceration, health problems, or death (Bengtson 2001; Cherlin and Furstenberg 1986; Kivett 1991; Song 2016). Their relationships with children also depend on the quality of their relationships with parents, geographic proximity, and their own health (Bol and Kalmijn 2016; Chan and Elder 2000; Zeng and Xie 2014). Moreover, their ability to transmit wealth or other resources to children depends on their own resources and needs as well as inheritance laws, and the benefits of such transfers (or the consequences of their absence) depend on the generosity of welfare-state policies (Mare 2011; Møllegaard and Jæger 2015).

Scholars merging this logic with the realities of contemporary developed societies paint contrasting pictures. Most agree that grandparents' opportunities to influence their grandchildren have never been greater: longer lifespans, improved health, and greater wealth have increased the potential for direct grandparental effects (Cherlin and Furstenberg 1986). Some expect this to translate into a greater impact on children's life chances, with grandparents playing a compensatory role amid the decline of the two-parent biological family (Bengtson 2001). Others expect grandparents' impact to be weakened in the current context, as the most consequential basic needs are increasingly met by the immediate family or are otherwise accessible through welfare systems (Coall and Hertwig 2010).

\section{Empirical Evidence on Multigenerational Inequality}

There is a small but growing empirical literature on multigenerational stratification. Most studies focus on testing direct grandparental status effects, which provides a litmus test for the Markov approach. Findings vary with research methodology, social context, and outcomes (Bol and Kalmijn 2016), but the bulk of the evidence echoes Hodge's (1966) early interpretation: 
grandparental socioeconomic status may have some influence on children's outcomes that is not mediated by parents, but it appears to be weak at best (Solon 2015). This is especially true in the U.S. (Hertel and Groh-Samberg 2014; Warren and Hauser 1997). Attributions of Residual Inequality

Most studies use the "residual method" and attribute multigenerational associations not explained by parent attributes to direct grandparental effects. The validity of this approach depends on how well the researcher measures and models the constructs that mediate indirect multigenerational effects. Not surprisingly, findings vary considerably depending on the way studies account for parent characteristics: direct effect estimates are typically smaller in studies that incorporate more data on parents (Bol and Kalmijn 2016; Warren and Hauser 1997) than in those that incorporate less parent information (Chan and Boliver 2013; Hertel and Groh-Samberg 2014; Kroeger and Thompson 2016; Pfeffer 2014). Omitting parent characteristics almost certainly leads analysts to misattribute indirect multigenerational effects (operating through grandparents' early influences on parents) to direct effects on children.

Unfortunately, parent attributes available in many datasets are limited to a few attainment measures such as educational and economic outcomes. Such measures are unlikely to capture many social and cultural processes by which grandparental status is transmitted through parents to children. Suppose higher-status grandparents are more likely than lower-status grandparents to promote the value of education to parents (as children), and that these parents tend to follow suit with their own children, which boosts their children's attainment (e.g., Roksa and Potter 2011). If this process occurs even among parents who fail to attain high levels of schooling, it indirectly transmits grandparental status through parents to children, irrespective of parents' attainment. Residual-based approaches that only control for parent attainment would misattribute such 
processes to direct grandparental effects. Accordingly, recent analyses of Swedish data indicate that accounting for parents' early family attributes and skills substantially reduces estimated multigenerational wealth effects on educational outcomes (Hällsten and Pfeffer 2017).

Another weakness of the residual method is that it implicitly compares unexplained grandparental effects to a baseline of zero, which may be inappropriate. Becker and Tomes (1979) note that after accounting for parents' status in a Markov intergenerational process, conditional (direct) associations between grandparents' and children's status should be negative (Solon 2014). This is because, among parents at a given level of attainment, those from more advantaged backgrounds are negatively selected in terms of luck or unobserved factors that might then affect their children; parents from more disadvantaged backgrounds are likely positively selected. This is a case of what causal inference scholars have called endogenous selection bias from conditioning on a "collider" variable (Elwert and Winship 2014; Pearl 2009). In this case, null conditional multigenerational associations could obscure direct grandparental influences that counter these selection effects.

\section{Mechanisms of Transmission}

Given the literature's emphasis on direct effects, we know less about the mechanisms comprising indirect effects. Song (2016) provides evidence that the family structure in which parents and children are raised helps mediate multigenerational effects on educational inequality. Wightman and Danzinger (2014) show that parents' family background and home environment during their own upbringing shape their children's home environment and educational attainment, and Roksa and Potter (2011) link grandparents' social class to children's academic achievement via parents' childrearing practices. Finally, Sharkey and Elwert (2011) find that childhood exposure to neighborhood poverty in both the parent and child generations affects 
children's cognitive ability. This all suggests that indirect multigenerational effects operate partly through the intergenerational transmission of familial and contextual experiences, often labeled as cultural inheritance or reproduction (Becker and Tomes 1979; Bourdieu and Passeron 1977).

If there are direct multigenerational effects, they must have explanations as well. Zeng and Xie (2014) make a strong case for grandparents' socioemotional influences. Grandparents who frequently interact with children can shape their intellectual environment, supervise their behavior, and serve as role models. Zeng and Xie's evidence from rural China, where grandparental coresidence is common, suggests a direct link between grandparents' and children's educational attainment, but only when grandparents live with children. This may be less consequential in the U.S., where grandparental coresidence is rare. Hällsten and Pfeffer (2017) note that direct multigenerational effects could also operate through things money buys, norms about education, or the safety net that wealth provides when making decisions. These explanations do not require much interpersonal contact between grandparents and children, and they could operate either by promoting children's skill development or by increasing children's preferences for education. Hällsten and Pfeffer (2017) suggest that normative mechanisms are most consequential in Sweden, but they speculate that the purchasing power facilitated by grandparental wealth may be more important in the U.S.

\section{Nonlinearities and Interactions}

Most studies seeking to adjudicate direct and indirect multigenerational effects are also based on regressions that imply linear and additive effects in the transmission process.

Nonlinearities or interactions in these processes may lead status persistence to be stronger at the top or bottom of the status hierarchy (Mare 2011). Prior research examining specific interactions suggests that grandparental status may alter the effects of children's family structure (Song 
2016), grandparental coresidence (Zeng and Xie 2014), parent income (Jæger 2012), and parents' childrearing practices (Roksa and Potter 2011) on children's educational outcomes. It remains to be seen how the constellation of such interactions contributes to multigenerational inequality, and how indirect and direct transmissions depend on grandparental status.

\section{This Study}

The present study harnesses data on parents' upbringing, skills, and educational orientations during their youth to better understand the indirect transmission of multigenerational inequality and to reduce omitted variable bias in analyses of direct multigenerational effects. This study also assesses explanations of direct effects by incorporating data on children's upbringing, including grandparental coresidence and children's home environments, skills, and educational orientations. My analyses rely on these potential mechanisms to avoid inferring direct effects from non-zero residual associations (net of parent controls); instead, I quantify direct effects based on how measured child attributes attenuate these residual associations. Finally, this study provides insights about whether these transmission processes differ for the those from the most advantaged and most disadvantaged backgrounds.

\section{Conceptual Model, Data, and Measures}

\section{Conceptual Model}

I follow the conceptual model in Figure 1. It includes the following constructs in three generations: antecedent characteristics and other controls exogenous or prior to grandparental attainment $\left(\mathrm{A}_{\mathrm{g}}\right)$; family attributes relevant to parents' $\left(\mathrm{F}_{\mathrm{p}}\right)$ and children's $\left(\mathrm{F}_{\mathrm{c}}\right)$ upbringing; parents' $\left(S_{p}\right)$ and children's $\left(S_{c}\right)$ skills and related attributes; parents' $\left(O_{p}\right)$ and children's $\left(O_{c}\right)$ educational orientations; and each generation's educational attainment $\left(\mathrm{E}_{\mathrm{g}}, \mathrm{E}_{\mathrm{p}}, \mathrm{E}_{\mathrm{c}}\right)$. I assume the temporal ordering is: $\mathrm{Ag}_{\mathrm{g}}, \mathrm{E}_{\mathrm{g}}, \mathrm{F}_{\mathrm{p}}, \mathrm{S}_{\mathrm{p}}, \mathrm{O}_{\mathrm{p}}, \mathrm{E}_{\mathrm{p}}, \mathrm{F}_{\mathrm{c}}, \mathrm{S}_{\mathrm{c}}, \mathrm{O}_{\mathrm{c}}, \mathrm{E}_{\mathrm{c}}$. This is an oversimplification of a 
complex dynamic process, but one that is consistent with prior intergenerational models (e.g., Sewell, Haller, and Ohlendorf 1970). Note that flaws in the causal ordering should be most problematic within generations; they should not affect inferences about the importance of direct and indirect multigenerational effects. As a robustness check, I replicate my analyses under a different order that places skills before family attributes (e.g., allowing parents to respond to children's skills).

The model allows grandparents' education to affect children's education directly as well as indirectly through any of the other constructs. ${ }^{1}$ The direct arrow $\left(E_{g} \rightarrow E_{c}\right)$ is debatable: in theory, it should be possible to account for all of the underlying mechanisms. After accounting for antecedents and controls, I treat all multigenerational inequality explained by constructs from parents' upbringing and attainment as indirect effects; this captures early grandparental influences on parents unlikely to be intended to influence children. I treat any remaining inequality explained by child-generation constructs as direct effects; this captures the effects of grandparent-child interactions as well as grandparental behaviors that influence children but are mediated by parents (e.g., parenting advice, money for children's education). I treat any residual inequality as unexplained rather than assuming it captures direct effects.

\section{Data}

Data come from the Child and Young Adult Cohorts of the National Longitudinal Survey of Youth 1979 (NLSCYA), which has followed over 11,500 children born to women from the original NLSY79 survey through 2014. NLSCYA is particularly relevant to contemporary stratification processes, as these children have recently completed, are currently completing, or will soon complete their educational attainment. Linking these children to their mothers in NLSY79 provides retrospective data on maternal grandparents and prospective longitudinal data 
on children and parents. The lack of data on paternal grandparents is unfortunate, and although it would be ideal to have data on all grandparents, this is the next-best alternative; theory and evidence suggest that maternal grandparents are more involved and influential than paternal grandparents in their support of their adult children and grandchildren (Chan and Elder 2000;

Coall and Hertwig 2010; Kivett 1991; Silverstein and Bengtson 1997).

\section{Grandparental Education}

I classify children into three grandparental education groups based on the highest grade completed by either maternal grandparent: low (less than $\left.12^{\text {th }}\right)$, middle $\left(12^{\text {th }}-15^{\text {th }}\right)$, and high $\left(16^{\text {th }}\right.$ or more). These roughly correspond to less than a high school diploma, high school completion or some college, and bachelor's degree attainment or more, respectively. I use the term multigenerational effects to describe disparities in children's education across these groups. I exclude 438 cases (3.8\%) missing grandparent education data. I reach similar conclusions under different methods of defining these groups (see supplement).

Using grandparent education matches my focus on intergenerational educational transmissions and makes sense given that intergenerational associations are generally strongest for like measures of attainment (Duncan et al. 2005; Haveman and Wolfe 1995). I do not aim to isolate causal effects of grandparental education, so I do not control for other components of grandparental socioeconomic status, although supplementary analyses consider grandparents' occupational status alongside education. This means that my analyses likely overstate the unique effects of grandparent education by capturing the effects of other correlated status components. From another perspective, my analyses likely understate the total influence of grandparents or grandparental status broadly construed (Clark and Cummins 2015; Jæger 2012).

\section{Outcomes}


The primary outcome variable is the child's highest grade completed. I treat education as missing if it is not observed at age 25 or older. $^{2}$ A weakness of these data is that many children are not old enough to have completed their education, and the NLSY79 sampling design ties this sample attrition to mothers' ages at birth. My analytic sample only includes children born to mothers by age 31 ; I expect it to be representative of all families with at least one such child (over $80 \%$ of the NLSY79). Nonetheless, the age cutoff for education data excludes 6,873 children, leaving 4,201. Although this only includes $38 \%$ of all children, it includes at least one child from half of the NLSY79 mothers and grandparents. If anything, direct multigenerational effects are likely to be more pronounced in this sample than a more representative one, because it is tilted toward earlier-born children, who will have more overlap with their grandparents' lifespans. Nonetheless, my conclusions are not altered when analyses are replicated with attrition weights, when using a larger sample with education data at age 23 or older, or when using the full sample with imputed outcomes; I also include maternal age at birth as a covariate.

As additional outcomes, I examine indicators of whether the child earned a high school diploma (not a GED), attended any college, and earned a bachelor's degree. I use a subset $(\mathrm{N}=3,753)$ of the primary sample due to some missing data confirming a high school diploma and college attendance; I replicate the highest grade analysis on this sample as well. Results are similar when using larger samples for these outcomes with earlier age cutoffs (supplement). Explanatory Variables

Several explanatory variables are scales constructed from multiple items. In these cases, I conduct age-specific factor analyses, after which I average available measures of each scale within specified age spans. Appendix Table A1 summarizes all scales, including specific items and scale reliabilities (all above 0.7). 
Antecedents and controls $\left(\mathrm{A}_{\mathrm{g}}\right)$ include other axes of stratification exogenous to or conceptually distinct from grandparents' attainment; they might be considered alternative sources of multigenerational educational associations. I control for mothers' race (black, Hispanic, or white), the nativity of maternal grandparents (immigrant vs. born in the U.S.), and the child's gender. Controlling gender prevents me from inadvertently introducing gender differences across groups when adjusting for covariates that may be correlated with gender.

Family upbringing refers to family structure and childrearing processes during childhood and adolescence. As measures of the mother's upbringing $\left(\mathrm{F}_{\mathrm{p}}\right)$, I include a scale of the home reading environment at age 14, an indicator of whether the mother lived in a two-parent biological family throughout childhood, and her number of siblings. For the child's upbringing, I separate two sets of variables. First $\left(\mathrm{F} 1_{\mathrm{c}}\right)$, I measure grandparent coresidence using an indicator of whether any grandparent lived with the child at any time from birth to age 18 . This accounts for inequality due to differences in coresidence. Second $\left(\mathrm{F} 2_{\mathrm{c}}\right)$, I include measures of cognitive stimulation and emotional support from the HOME inventory at ages $0-14$; the mother's age at the child's birth; sibship size; and indicators of whether the child lived with a two-parent biological family throughout ages 0-18 (reference), some of that time (disruption), or none of that time (never). These constructs capture indirect and direct transmissions related to family processes and childrearing practices (Lareau 2003; McLanahan and Percheski 2008).

Skills and personal attributes refer to the skills, self-perceptions, and behaviors that shape educational outcomes. For mothers $\left(\mathrm{S}_{\mathrm{p}}\right)$, I include percentile scores on the AFQT achievement test, a scale measuring self-reported delinquent behaviors and drug use, and a measure of locus of control, all collected between ages 14 and 22. For children $\left(\mathrm{S}_{\mathrm{c}}\right)$, I include an intellectual skills scale based on standardized tests (ages 9-14); a behavior problems scale based on maternal 
reports (9-14); a self-perceived scholastic ability scale from the Self-Perceptions Profile for Children (9-14); and scales measuring delinquent behaviors and drug use from self-reports (918). These constructs capture direct and indirect influences operating via cognitive and socioemotional skill development (Becker and Tomes 1979; Farkas 2003).

Between skills and educational attainment in each generation are educational orientations. For mothers $\left(\mathrm{O}_{\mathrm{p}}\right)$, I include educational aspirations and expectations in 1979 (ages 14-21). For children $\left(\mathrm{O}_{c}\right)$, I include parental expectations for children at ages 9-14 and children's own aspirations and expectations at ages 15-18. These variables are measured as the highest grade of school desired or expected; they capture indirect and direct normative or social psychological transmissions (Morgan 1998; Sewell, Haller, and Portes 1969).

Between the constructs pertaining to parents and children is parent attainment, which I divide into two sets of measures. The first is educational attainment $\left(\mathrm{E} 1_{\mathrm{p}}\right)$, which may directly influence children's educational preferences (Breen and Goldthorpe 1997). I include fivecategory measures of schooling (less than high school, high school diploma, some college, bachelor's degree, graduate degree) for the child's mother and father. I also include the average years of schooling among all maternal aunts and uncles. The latter may capture normative effects of extended family members' attainment (Jæger 2012), as well as the residual influence of other unobserved or poorly measured parent attributes correlated with education.

The second set is parents' economic attainment $(\mathrm{E} 2 \mathrm{p})$. I include log-transformed average family income and average family net worth (2010 dollars) throughout the child's upbringing (ages 0-18). By including economic attainment here, I follow prior work and treat it as a way to capture indirect grandparent-parent-child transmissions. This is debatable, however, given my prior distinction of direct and indirect effects. These measures could capture grandparents' 
bequests to parents (or other grandparental actions that influence parents' economic behaviors) during children's upbringing that benefit children, which I deem direct effects. Isolating their contribution in a separate step allows me to consider either approach.

\section{Descriptive Statistics and Missing Data}

[Table 1. Descriptive Statistics by Grandparental Education]

Table 1 summarizes these measures, grouped by construct, for each of the three grandparental education groups in the analytic sample. All variables are patterned as expected, with the most favorable distribution of attributes in the high group and the least favorable distribution in the low group-I discuss more details in the results section. The table also includes the number of nonmissing observations for each variable. I address missing data using multiple imputation with chained equations. Prior to dropping cases with missing outcomes, I conduct separate imputations for each grandparental education group using predictive mean matching to relax functional form assumptions. All analyses are performed separately on each of 30 imputed data sets, excluding cases with imputed outcomes (although the outcome is included in all imputation models), and the results are pooled appropriately (Little and Rubin 2002).

\section{Methods}

Like most studies examining direct multigenerational effects, I use regression analyses, first estimating total grandparent education effects, then estimating conditional effects after introducing controls (e.g., Bol and Kalmijn 2016; Møllegaard and Jæger 2015). I modify the typical approach to capture nonlinear multigenerational effects by using indicators for three grandparent education groups, separating the high-middle and middle-low gaps. I then fit regressions that interact all covariates with grandparent education to permit differential effects across groups. ${ }^{3}$ Explaining inequality in a regression framework entails examining predicted 
group outcome differences conditional on the predictors; that is, after eliminating covariate disparities. Doing so amid effect heterogeneity requires a reference group; my primary analyses use the middle group. This means that I account for the portion of inequality explained by giving the high and low groups the middle group's covariate distribution (means), while allowing covariates to have group-specific effects. This has the advantage of separating the respective contributions of the low group's disadvantages and the high group's advantages, and it allows me to assess differences in the transmission process at the high and low ends of the grandparental education distribution. I also present results with other reference groups and without interactions. All analyses adjust standard errors for clustering within multigenerational families.

\section{Omitting Parent Attributes}

The first portion of the analysis assesses the empirical importance of parent controls when estimating direct multigenerational effects. I compare naïve direct effects (outcome gaps by grandparent education) estimated net of parents' attainment to more defensible estimates after adding the aforementioned covariates for the parent-generation constructs: antecedents and controls; mothers' family upbringing, skills, and educational orientations; and the average schooling of maternal aunts and uncles. I repeat this with two different parent attainment batteries: the first includes both mothers' and fathers' educational attainment, typical of studies with limited parent data; the second adds parent family income and wealth during the child's upbringing. I compare analyses with and without grandparent education interactions.

\section{Decomposition}

The second part of the analysis probes the multigenerational process more thoroughly to assess direct and indirect effects. I fit a sequence of regressions with all covariates interacted by grandparent education based on the conceptual model's ordering, and I execute a decomposition 
that calculates the portion of inequality attributed to each construct (i.e., the reduction in multigenerational gaps at each step). ${ }^{4}$ Equations 1.1-1.3 show a sequence of three regressions. The baseline specification (1.1) includes indicators for the high $\left(E_{g}=H\right)$ and low $\left(E_{g}=L\right)$ grandparent education groups, with the middle $\left(E_{g}=M\right)$ as the reference. The second specification (1.2) adds one set of covariates $\left(X_{1}\right)$, and the third (1.3) adds an additional set $\left(X_{2}\right)$. The $\alpha_{H-M}$ and $\alpha_{M-L}$ parameters capture the conditional high-middle and middle-low gaps at each step. $E\left(Y \mid E_{g}\right)=\alpha_{M}+\alpha_{H-M} H-\alpha_{M-L} L$

$E\left(Y \mid E_{g}, X_{1}\right)=\alpha_{M}^{\prime}+\alpha_{H-M}^{\prime} H-\alpha_{M-L}^{\prime} L+X_{1} \beta_{M}^{\prime}+\left(X_{1} \times H\right) \beta_{H-M}^{\prime}-\left(X_{1} \times L\right) \beta_{M-L}^{\prime}$ $E\left(Y \mid E_{g}, X_{1}, X_{2}\right)=\alpha_{M}^{\prime \prime}+\alpha_{H-M}^{\prime \prime} H-\alpha_{M-L}^{\prime \prime} L+X_{1} \beta_{M}^{\prime \prime}+\left(X_{1} \times H\right) \beta_{H-M}^{\prime \prime}-\left(X_{1} \times L\right) \beta_{M-L}^{\prime \prime}+X_{2} \gamma_{M}^{\prime \prime}+$ $\left(X_{2} \times H\right) \gamma_{H-M}^{\prime \prime}-\left(X_{2} \times L\right) \gamma_{M-L}^{\prime \prime}$

Equations 2.1-2.4 show four components of a decomposition of the high-middle gap: $E\left(Y \mid E_{g}^{H}\right)-E\left(Y \mid E_{g}^{M}\right)$. The middle-low decomposition is similar, and the high-low decomposition sums the high-middle and middle-low components. The raw gap comes from the first regression (2.1); the reduction in the gap across the first two regressions captures the component explained by the first set of covariates (2.2); the reduction across the second and third regressions captures the component explained by the second set (2.3); and the residual gap in the third regression remains unexplained (2.4). I estimate the conditional gaps at each step with covariates held at the reference (middle) group's averages (e.g., $\bar{X}_{1}^{M}, \bar{X}_{2}^{M}$ ). Any step that adds covariates from the parent generation contributes to indirect effects; any step that adds covariates from the child generation contributes to direct effects.

$$
\begin{aligned}
& E\left(Y \mid E_{g}^{H}\right)-E\left(Y \mid E_{g}^{M}\right)=\alpha_{H-M} \\
& {\left[E\left(Y \mid E_{g}^{H}, \bar{X}_{1}^{M}\right)-E\left(Y \mid E_{g}^{M}, \bar{X}_{1}^{M}\right)\right]-\left[E\left(Y \mid E_{g}^{H}\right)-E\left(Y \mid E_{g}^{M}\right)\right]=\alpha_{H-M}-\alpha_{H-M}^{\prime}} \\
& {\left[E\left(Y \mid E_{g}^{H}, \bar{X}_{1}^{M}, \bar{X}_{2}^{M}\right)-E\left(Y \mid E_{g}^{M}, \bar{X}_{1}^{M}, \bar{X}_{2}^{M}\right)\right]-\left[E\left(Y \mid E_{g}^{H}, \bar{X}_{1}^{M}\right)-E\left(Y \mid E_{g}^{M}, \bar{X}_{1}^{M}\right)\right]=\alpha_{H-M}^{\prime}-\alpha_{H-M}^{\prime \prime}}
\end{aligned}
$$


$E\left(Y \mid E_{g}^{H}, \bar{X}_{1}^{M}, \bar{X}_{2}^{M}\right)-E\left(Y \mid E_{g}^{M}, \bar{X}_{1}^{M}, \bar{X}_{2}^{M}\right)=\alpha_{H-M}^{\prime \prime}$

This decomposition, though based on a fairly standard sequence of regressions, has a specific interpretation. It reveals, based on the assumed causal ordering, the points at which disparities in the intervening constructs that influence child attainment first emerge in the grandparent-parent-child chain of transmissions; in other words, it shows how far back we can trace multigenerational inequality in children's outcomes. It does so by capturing the direct associations between grandparental education and the mediating variables added at each step, coupled with those variables' total (direct and indirect) associations with the outcome. For parents' skills, for instance, this decomposition captures any direct link between grandparents' education and parents' skills not explained by antecedents or parents' family upbringing, combined with all of the direct and indirect influences of parents' skills on children's attainment.

In the context of the conceptual model, this decomposition reveals the extent to which multigenerational educational inequality is explained by persistent effects of antecedents and controls such as race and nativity $\left(\mathrm{A}_{\mathrm{g}}\right)$; indirect effects via grandparents' early influences on parents' attributes $\left(\mathrm{F}_{\mathrm{p}}, \mathrm{S}_{\mathrm{p}}, \mathrm{O}_{\mathrm{p}}\right)$ and attainment $\left(\mathrm{E}_{\mathrm{p}}\right)$; and direct effects via grandparents' later influences on children's attributes $\left(\mathrm{F}_{\mathrm{c}}, \mathrm{S}_{\mathrm{c}}, \mathrm{O}_{\mathrm{c}}\right)$. Capturing direct effects in this way avoids problems with making questionable inferences from non-zero residual gaps. I treat residual gaps after the final step as unexplained, due to direct or indirect effects via unmeasured mediators.

The analyses just described use OLS regressions when the outcome is the highest completed grade of schooling. For discrete outcomes, I repeat this procedure with logistic regressions. I estimate multigenerational gaps using predicted outcome probabilities, and I base the decomposition components on changes in these gaps at each step in the sequence. To 
maintain comparability with the OLS analyses, I focus on the percentage reduction in the multigenerational gaps across steps for these outcomes.

Note that I will not focus much on specific coefficients or interactions, but rather on their aggregated contributions to multigenerational inequality by construct and generation. Focusing on specific covariates introduces concerns with collinearity and overcontrolling when assessing conceptually related variables. Moreover, focusing on coefficients can be deceptive, because a variable's contribution to inequality depends not only on its effects, but also on differences in its levels across groups net of other covariates in the model. Also note that I use the term "effects" loosely. Causal claims about direct or indirect effects are unwarranted for the typical reasons when using observational data; this is especially true when attributing inequality to specific constructs within generations, which are likely sensitive to the assumed temporal ordering. I aim to provide a rich though imperfect accounting of multigenerational inequality that probes the explanatory power of theoretically motivated constructs.

\section{Results}

Typical of intergenerational stratification patterns, Table 1 reveals a mix of educational mobility and reproduction across generations. There is impressive convergence in attainment, with those from the low and middle groups making greater progress than those from the high group; much of this occurred in the parent generation. High school graduation rates fell for parents and children in the middle and high groups; they rose substantially for parents and held steady for children in the low group. Bachelor's degree attainment rates fell for parents and rose slightly for children in the high group; they rose across both generations in the low and middle groups. Nonetheless, notable disparities remain: children from the high group average 14.8 grades of school, have high school completion and college attendance rates well above $80 \%$, and 
have bachelor's degree attainment rates of 49\%; those from the low group average 12.7 grades of school, with only $67 \%$ graduating high school, $54 \%$ attending college, and $17 \%$ earning bachelor's degrees; the middle group lies in between.

\section{Direct Effect Estimates with Parent Controls}

[Figure 2. Direct Effects and Parent Controls]

Figure 2 summarizes the sensitivity of direct multigenerational effect estimates to the incorporation of parent controls (additional details in supplement). The outcome is the highest completed grade of school. Focusing on the high-low gap at the bottom of Figure 2, controlling both parents' education yields a statistically significant 1.0-grade gap in educational attainment as the naïve direct effect estimate, about half of the raw gap (2.1). The gap is still significant at 0.9 grades after interacting parents' attainment with grandparents' education. Including the additional parent controls (antecedents, maternal upbringing, skills, educational orientations, aunts'/uncles' education) leaves a non-significant 0.2-grade gap; permitting interactions with grandparents' education virtually eliminates the gap.

Supplementing parent education with income and wealth fares better, but still yields a significant 0.65 -grade gap as the naïve direct effect estimate. This is eliminated with additional parent controls. The same pattern appears for both the high-middle and middle-low gaps. It also appears that failing to account for interactions overstates the direct effect of high-status grandparents, even with additional parent controls: the marginally significant 0.3 -grade gap for the high-middle comparison is cut to a non-significant 0.1-grade gap with interactions. Recall that these gaps are predicted when all groups have the middle group's covariate distribution; I consider different reference groups and specific interactions later. 
In all of these analyses, the differences in direct effect estimates with and without the additional parent controls — which could be construed as a measure of bias—are statistically significant (supplement). Additional analyses show that grandparent occupational status effects, which are significant when included alongside grandparent education, are also eliminated with parent controls (supplement). In short, analyses of direct multigenerational effects are misleading with controls for parent attainment only. A nontrivial portion of multigenerational educational inequality operates through grandparents' early influences on parents in ways that do not depend on parents' attainment.

Sequential Decomposition: Highest Grade of Schooling

[Table 2. Sequential Decomposition: Highest Grade Completed]

Although parent controls eliminate almost all of the raw multigenerational attainment gaps, this does not preclude direct multigenerational effects, and we can explore potential underlying mechanisms with the sequential decomposition analysis summarized in Table 2 (Appendix Table A2 includes specific regression coefficients). Of the 2.13-grade gap between the high and low groups, antecedents and parent traits completely eliminate it, accounting for 2.16 grades $(101.6 \%)$. The decomposition attributes $13.9 \%$ to antecedents/controls, $22.8 \%$ to mothers' upbringing, $39.5 \%$ to mothers' skills, $14.0 \%$ to mothers' educational orientations, and $8.7 \%$ to parents' and maternal aunts' and uncles' education. Each of these components is statistically significant. Another $2.7 \%$ is attributed to parents' economic attainment (not significant); although some portion of this could be construed as a direct effect, it would make little difference. An alternative analysis that allows skills to precede family upbringing attributes more inequality to mothers' skills (50.0\%) and less to their upbringing (12.2\%) (supplement). 
Overall, this suggests that a variety of mechanisms contribute to indirect multigenerational transmissions, including persistent effects of race and ethnicity, cultural transmissions related to childrearing, nature and nurture effects on skill development, and social psychological influences on educational orientations. Regardless of the assumed ordering, mothers' skills make the largest contribution — over three-fourths of a grade level—and both cognitive (AFQT) and noncognitive skills (delinquency) are significant predictors (Table A2).

Although parent traits completely eliminate the raw gap, I have argued that direct effects could be obscured by selection effects. Accordingly, measured child attributes account for 0.13 grades $(6.0 \%)$ of the high-low gap, leaving a negative unexplained component (-0.16 grades, 7.5\%). This affirms that the residual method can conceal direct transmissions when conditional associations are negative. The totality of direct effects is modest, however, and none of the specific components are statistically significant. This is true regardless of attrition weights, the ordering of constructs, or the definition of grandparent education groups (supplement).

To the extent that these analyses reveal any direct effects, the point estimates suggest that children's family upbringing (5.5\%) and educational orientations (4.5\%) might contribute through cultural or social psychological mechanisms. Child skills $(-4.2 \%)$ work in the opposite direction; though skills do affect attainment, the skills of children from high-education backgrounds compare poorly to those of children from low-education backgrounds after accounting for their other advantages. Along with the negligible contribution of grandparent coresidence, this suggests that direct influences on cognitive and socioemotional development contribute little to multigenerational inequality in the U.S. These patterns hold even when skills precede family upbringing in the sequential decomposition.

\section{Nonlinearities and Interactions}


Comparing the high-middle and middle-low gaps suggests nonlinear multigenerational effects: the high-middle gap $(\mathrm{H}-\mathrm{M}=1.41$ grades $)$ is twice as large as the middle-low gap $(\mathrm{M}-\mathrm{L}=$ 0.72). Whether there is heterogeneity in the transmission of advantage and disadvantage depends on the combination of group differences in covariate levels and effects; this is very difficult to test statistically given the differences in the magnitude of the high-middle and middle-low gaps. I use three methods to probe these differences, although my interpretations are subjective and this evidence should be viewed as tenuous.

First, I compare the portions of the high-middle and middle-low gaps explained by specific constructs in the sequential decomposition; this captures the aggregated combination of group differences in covariate levels and effects, but it is not amenable to simple statistical tests. Second, I assess interaction coefficients (Table A2); this captures differences in specific covariate effects and accommodates statistical tests, but it does not capture the contribution these differences make overall at the construct level. Third, I alter the reference group in the decomposition. With the middle group as a reference, I capture the inequality explained by giving the high and low groups the middle group's attributes. If the low group was the reference, I would capture the inequality explained by giving the high and middle groups the low group's attributes. When variables have different effects across groups, components depend on the reference: constructs with stronger effects in the high group will explain more inequality when the low group is the reference, and constructs with stronger effects in the low group will explain more inequality when the high group is the reference..$^{5}$ Appendix Table A3 summarizes generation-aggregated components using different reference groups.

Together, these analyses suggest that antecedents related to race/ethnicity explain slightly more of the multigenerational transmission of advantage than disadvantage. First, they explain 
$15.3 \%$ of the high-middle gap compared to $11.1 \%$ of the middle-low gap with the middle group as a reference. Second, they explain more inequality when the low group is the reference and less when the high group is the reference, and this is more pronounced for the high-middle than the middle-low gap. Third, the interaction coefficients (Table A2) highlight a larger penalty for being black or Hispanic among the high group. Highly-educated grandparents are more likely to be white, which facilitates the transmission of advantage across generations.

Otherwise, there is some evidence that more of the transmission of disadvantage is indirect, whereas more of the transmission of advantage is direct, but this evidence is mixed. With respect to the former, parent attributes explain more of middle-low (110.1\%) than the highmiddle (76.3\%) gap with the middle group as reference, and interactions suggest that mothers' delinquent behaviors may have more deleterious effects in the low and middle groups. Yet there is no clear pattern when altering the reference group. With respect to the latter, child attributes explain more of the transmission of advantage (12.0\% H-M vs. $-5.9 \% \mathrm{M}-\mathrm{L})$, this is most pronounced when the low group is the reference, and interactions suggest that cognitive stimulation has stronger effects among those from more advantaged backgrounds. Yet these differences do not hold when adjusting for attrition (supplement).

\section{Other Outcomes}

[Table 3. Summary of Sequential Decompositions for All Outcomes] [Figure 3. Sequential Decomposition, All Outcomes]

Table 3 summarizes the decompositions for all four outcomes (limited to the 3,753 cases with complete data on all outcomes), adding high school diploma, college attendance, and bachelor's degree attainment. These analyses use the middle group as a reference; the supplement includes more detailed tables and analyses with different samples and reference 
groups. Figure 3 summarizes the results by plotting the percentages of the raw gaps remaining at each stage in the sequence. Because these analyses use different methods, and because the outcomes have different raw gaps, I cannot draw strong conclusions about differences in components across outcomes; here I explore general patterns. An overriding similarity is that the vast majority of explained inequality for each outcome is attributable to antecedents and parent attributes; relatively little is attributed to measured child attributes. Nonetheless, there are some notable exceptions.

Much more inequality remains unexplained for high school completion and college attendance than for highest grade or bachelor's degree attainment. It is the latter outcome, however, for which there is more evidence of direct effects. Child attributes explain $25.9 \%$ of the high-low gap in bachelor's degree attainment, about 8 percentage points. In this case, as with highest grade completed, direct effects may be more important to the transmission of advantage (H-M, 37.5\%, 8.8 points) than disadvantage (M-L, $-5.0 \%$ ), driven mainly by the greater contribution of advantaged children's educational orientations. Also echoing the highest grade analyses, antecedents explain more of the transmission of advantage than disadvantage for bachelor's degree attainment, and parent attributes and attainment explain more of the transmission of disadvantage. For high school completion and college attendance, parent attributes explain most inequality, and mothers' upbringing and skills make the largest contributions. There is no evidence of direct effects for these outcomes; child attributes combine to make negative contributions. These patterns hold in alternative samples (supplement).

\section{Discussion}

To the extent that I can offer a concise summary of these findings, I make three points. First, there is substantial multigenerational educational inequality, most (but not all) of which 
can be explained in a Markov intergenerational framework, with a chain of grandparent-parentchild transmissions. Second, conventional methods of assessing direct multigenerational effects using residual grandparent-child associations have serious flaws, which can lead us to either overestimate or underestimate direct effects. Third, there are practical ways to overcome these flaws, and they yield some noteworthy findings.

The first contribution is showing that parent attainment measures - even when they include parents' education, income, and wealth - are insufficient to account for all of the indirect influences grandparental status has on children's education. Grandparents influence parents' upbringing and development in a number of ways that shape subsequent parental influences on children, irrespective of parents' socioeconomic attainment. My decomposition analyses, though descriptive and contingent on the assumed causal ordering, are consistent with independent contributions from mechanisms spanning several theoretical domains, including those involving familial resources and educational environments (Blau and Duncan 1967; Lareau 2003; McLanahan and Percheski 2008; Roksa and Potter 2011), skill or human capital development (Becker and Tomes 1986; Farkas 2003), and educational goals and expectations (Breen and Goldthorpe 1997; Sewell, Haller, and Ohlendorf 1970). Even among parents who surpass or fall short of the attainment typical of their origins, these effects linger in ways that affect their children. After accounting for a variety of such parent attributes, multigenerational associations for educational attainment are generally negligible.

The second contribution is showing that these negligible residual associations do not mean there is no room for direct multigenerational effects. As Becker and Tomes (1979) first noted, controlling for parent attainment induces unobserved selection in such a way that direct associations in a Markov process should be negative. That is, null associations net of parent traits 
remain consistent with direct multigenerational effects. Even without a clear baseline from which to assess direct effects, we can capture them using measured child attributes related to plausible mechanisms of direct transmissions. I do so by incorporating measures of children's family resources and environments during their upbringing, their cognitive and noncognitive skills, and their educational orientations into a sequential regression analysis and decomposition. Overall, I find little evidence of direct effects, although bachelor's degree attainment is a notable exception: direct effects explain 6-8 points of the multigenerational gap in degree completion.

The third contribution is the ability to explore some specific and theoretically salient mechanisms underlying direct effects. Again, the findings are descriptive and contingent on the causal ordering, but they suggest that the child traits that account for the most inequality are characteristics of their family upbringing and educational orientations. Children's cognitive and noncognitive skills play less of a role, and grandparent coresidence is irrelevant. This is consistent with prior speculation that direct grandparental influences via childrearing and cognitive and socioemotional development are relatively inconsequential in the U.S. (Zeng and Xie 2014). Instead, the evidence here is more consistent with direct cultural or normative transmissions, both of which would operate through children's home environments and educational goals or expectations (Hällsten and Pfeffer 2017).

The fourth contribution is exploring differences in the nature of multigenerational transmissions between those from the most advantaged and disadvantaged backgrounds. There is no simple way to make statistical inferences about such differences, but the findings do reveal patterns worthy of further consideration. The most robust evidence suggests that racial/ethnic minority status comes with a larger penalty among those from the most advantaged backgrounds. This suggests that it is more difficult for minorities to transmit educational advantage across 
generations; since those from the most advantaged backgrounds are disproportionately white, it also helps explain the persistence of advantage at the top of the educational hierarchy. There is also some evidence, though it is less convincing, that indirect transmissions through parents' early experiences and skills contribute more to the reproduction of disadvantage, whereas direct transmissions through children's family upbringing and educational orientations contribute more to the reproduction of advantage.

Again, this is ultimately an observational analysis, and it is worth repeating the call for caution when interpreting specific components or variables. Incorporating measures of child attributes is not a foolproof way to capture direct effects if adequate parent controls are lacking. Indirect transmissions through unmeasured parent attributes and measured child attributes might still lead me to overstate direct effects. Nonetheless, this approach lends more face validity to direct effect estimates, and my analyses reveal examples where substantial amounts of unexplained inequality are not misattributed to direct effects (high school completion and college attendance). Poorly measured constructs may distort the decomposition analyses as well. Mothers' family upbringing, in particular, seems crudely measured, and there are no measures of fathers' upbringing, skills, or educational orientations. It is unclear how much paternal measures might contribute; mothers' attributes tend to be more consequential to children's attainment, and there is substantial homophily among parents (Schwartz 2013). There are also areas of ambiguity in distinguishing direct and indirect effects, both conceptually and empirically. This is partly because the data do not include details on grandparent behaviors or their intent; grandparental financial transfers to adult parents that might benefit children are one example. The data also lack comprehensive information on grandparental financial support for children's education, which might leave some direct effects unexplained. 
Focusing on grandparent education gaps also limits the scope of this study in a few ways. First, it ignores the way demographic processes such as fertility, mortality, and migration combine with multigenerational transmissions to shape population-level inequality (Mare 2011). Second, it ignores other aspects of grandparental status that may influence children's attainment (Clark and Cummins 2015; Jæger 2012). This is one reason to suspect that I have underestimated the extent of multigenerational inequality, broadly construed. Other dimensions of grandparental status could also have direct effects, which might contribute to (or be independent of) those I attribute to grandparent education. Additionally, it is possible that multigenerational stratification processes differ for other outcomes such as economic attainment; these data will be better suited to address this issue in the future as these children age.

In the end, the findings suggest that despite considerable educational mobility across the past three generations in the U.S., a substantial amount of inequality has persisted. Most of this has occurred via intergenerational transmissions from grandparents to parents to children. Yet there are also signs of direct grandparent-child transmissions, and there are hints of differences in the transmission of extreme advantage and disadvantage. Both warrant further research, which I hope will improve on the efforts made here. 


\section{ABOUT THE AUTHORS}

Jeremy E. Fiel is an Assistant Professor of Sociology at the University of Arizona. His research uses quantitative methods to examine problems of educational inequality and social stratification, with particular interests in contemporary school segregation and in processes of intergenerational stratification. Jeremy's work has been published in American Sociological Review, American Journal of Sociology, Social Forces, Demography, and American Educational Research Journal. 


\section{REFERENCES}

Becker, Gary S., and Nigel Tomes. 1979. "An Equilibrium Theory of the Distribution of Income and Intergenerational Mobility." Journal of Political Economy 87(6):1153-1189. 1986. "Human Capital and the Rise and Fall of Families." Journal of Labor Economics 4(3):S1-S39.

Behrman, Jere R., Robert A. Pollak, and Paul Taubman. 1995. From Parent to Child: Intrahousehold Allocations and Intergenerational Relations in the United States. Chicago: University of Chicago Press.

Bengtson, Vern L. 2001. "Beyond the Nuclear Family: The Increasing Importance of Multigenerational Bonds." Journal of Marriage and Family 63(1):1-16.

Blau, Peter Michael, and Otis Dudley Duncan. 1967. The American Occupational Structure. New York: Wiley.

Bol, Thijs, and Matthijs Kalmijn. 2016. "Grandparents' Resources and Grandchildren's Schooling: Does Grandparental Involvement Moderate the Grandparent Effect?" Social Science Research 55:155-170.

Bourdieu, Pierre. 1986. "The Forms of Capital." In Handbook of Theory and Research for the Sociology of Education, edited by John G. Richardson, 241-258. New York: Greenwood.

Bourdieu, Pierre, and Jean Claude Passeron. 1977. Reproduction in Education, Society and Culture. London: Sage Publications.

Breen, Richard, and John H. Goldthorpe. 1997. "Explaining Educational Differentials: Towards a Formal Rational Action Theory." Rationality and Society 9(3):275-305.

Chan, Christopher G., and Glen H. Elder. 2000. "Matrilineal Advantage in GrandchildGrandparent Relations." Gerontologist 40(2):179-190.

Chan, Tak Wing, and Vikki Boliver. 2013. "The Grandparents Effect in Social Mobility: Evidence from British Birth Cohort Studies." American Sociological Review 78(4):662678.

Cherlin, Andrew J., and Frank F. Furstenberg. 1986. The New American Grandparent: A Place in the Family, a Life Apart. New York: Basic Books.

Clark, Gregory, and Neil Cummins. 2015. "Intergenerational Wealth Mobility in England, 18582012: Surnames and Social Mobility." The Economic Journal 125(582):61-85.

Coall, David A., and Ralph Hertwig. 2010. "Grandparental Investment: Past, Present, and Future." Behavioral and Brain Sciences 33(1):1-19.

Coleman, James S. 1988. "Social Capital in the Creation of Human Capital." American Journal of Sociology 94:S95-S120.

Duncan, Greg J., Ariel Kalil, Susan E. Mayer, Robin Tepper, and Monique R. Payne. 2005. "The Apple Does Not Fall Far from the Tree." In Unequal Chances: Family Background and Economic Success, edited by Samuel Bowles, Herbert Gintis and Melissa Osborne Groves, 23-79. Princeton, NJ: Princeton University Press.

Elman, Cheryl, and Angela M O'Rand. 2004. "The Race Is to the Swift: Socioeconomic Origins, Adult Education, and Wage Attainment." American Journal of Sociology 110(1):123160.

Elwert, Felix, and Christopher Winship. 2014. "Endogenous Selection Bias: The Problem of Conditioning on a Collider Variable." Annual Review of Sociology 40:31-53.

Farkas, George. 2003. "Cognitive Skills and Noncognitive Traits and Behaviors in Stratification Processes." Annual Review of Sociology 29:541-562. 
Friedman, Debra, Michael Hechter, and Derek Kreager. 2008. "A Theory of the Value of Grandchildren." Rationality and Society 20(1):31-63.

Hallsten, Martin. 2014. "Inequality across Three and Four Generations in Egalitarian Sweden: 1st and 2nd Cousin Correlations in Socio-Economic Outcomes." Research in Social Stratification and Mobility 35:19-33.

Hällsten, Martin, and Fabian T. Pfeffer. 2017. "Grand Advantage: Family Wealth and Grandchildren's Educational Achievement in Sweden." American Sociological Review 82(2):328-360.

Haveman, Robert, and Barbara Wolfe. 1995. "The Determinants of Children's Attainments: A Review of Methods and Findings." Journal of Economic Literature 33(4):1829-1878.

Heckman, James J. 2006. "Skill Formation and the Economics of Investing in Disadvantaged Children." Science 312(5782):1900-1902.

Hertel, Florian R., and Olaf Groh-Samberg. 2014. "Class Mobility across Three Generations in the U.S. And Germany." Research in Social Stratification and Mobility 35:35-52.

Hodge, Robert W. 1966. "Occupational Mobility as a Probability Process." Demography 3(1):19-34.

Hogan, Dennis P., David J. Eggebeen, and Clifford C. Clogg. 1993. "The Structure of Intergenerational Exchanges in American Families." American Journal of Sociology 98(6):1428-1458.

Jæger, Mads Meier. 2012. "The Extended Family and Children's Educational Success." American Sociological Review 77(6):903-922.

Kivett, Vira R. 1991. "The Grandparent-Grandchild Connection." Marriage \& Family Review 16(3-4):267-290.

Kroeger, Sarah, and Owen Thompson. 2016. "Educational Mobility across Three Generations of American Women." Economics of Education Review 53:72-86.

Lareau, Annette. 2003. Unequal Childhoods: Class, Race, and Family Life. Berkeley, CA: University of California Press.

Little, Roderick J. A., and Donald B. Rubin. 2002. Statistical Analysis with Missing Data. Hoboken, NJ: Wiley.

Mare, Robert D. 2011. "A Multigenerational View of Inequality." Demography 48(1):1-23. . 2014. "Multigenerational Aspects of Social Stratification: Issues for Further Research." Research in Social Stratification and Mobility 35:121-128.

McLanahan, Sara, and Christine Percheski. 2008. "Family Structure and the Reproduction of Inequalities." Annual Review of Sociology 34:257-276.

Møllegaard, Stine, and Mads Meier Jæger. 2015. "The Effect of Grandparents' Economic, Cultural, and Social Capital on Grandchildren's Educational Success." Research in Social Stratification and Mobility 42:11-19.

Morgan, Stephen L. 1998. "Adolescent Educational Expectations: Rationalized, Fantasized, or Both?" Rationality and Society 10(2):131-162.

Mulligan, Casey B. 1997. Parental Priorities and Economic Inequality. Chicago: University of Chicago Press.

Nielsen, François. 2006. "Achievement and Ascription in Educational Attainment: Genetic and Environmental Influences on Adolescent Schooling." Social Forces 85(1):193-216.

Pearl, Judea. 2009. Causality. Cambridge: Cambridge University Press.

Pfeffer, Fabian T. 2014. "Multigenerational Approaches to Social Mobility: A Multifaceted Research Agenda." Research in Social Stratification and Mobility 35:1-12. 
Plomin, Robert, Michael J. Owen, and Peter McGuffin. 1994. "The Genetic Basis of Complex Human Behaviors." Science 264(5166):1733-1739.

Roksa, Josipa, and Daniel Potter. 2011. "Parenting and Academic Achievement: Intergenerational Transmission of Educational Advantage." Sociology of Education 84(4):299-321.

Schwartz, Christine R. 2013. "Trends and Variation in Assortative Mating: Causes and Consequences." Annual Review of Sociology 39(1):451-470.

Sewell, William H., Archibald O. Haller, and George W. Ohlendorf. 1970. "The Educational and Early Occupational Status Attainment Process: Replication and Revision." American Sociological Review 35(6):1014-1027.

Sewell, William H., Archibald O. Haller, and Alejandro Portes. 1969. "The Educational and Early Occupational Attainment Process." American Sociological Review 34(1):82-92.

Sharkey, Patrick, and Felix Elwert. 2011. "The Legacy of Disadvantage: Multigenerational Neighborhood Effects on Cognitive Ability." American Journal of Sociology 116(6):1934-1981.

Silverstein, Merril, and Vern L. Bengtson. 1997. "Intergenerational Solidarity and the Structure of Adult Child Parent Relationships in American Families." American Journal of Sociology 103(2):429-460.

Solon, Gary. 2014. "Theoretical Models of Inequality Transmission across Multiple Generations." Research in Social Stratification and Mobility 35:13-18. . 2015. "What Do We Know So Far About Multigenerational Mobility?" National Bureau of Economic Research Working Paper Series No. 21053.

Song, Xi. 2016. "Diverging Mobility Trajectories: Grandparent Effects on Educational Attainment in One- and Two-Parent Families in the United States." Demography 53(6):1905-1932.

Warren, John Robert, and Robert M. Hauser. 1997. "Social Stratification across Three Generations: New Evidence from the Wisconsin Longitudinal Study." American Sociological Review 62(4):561-572.

Wightman, Patrick, and Sheldon Danziger. 2014. "Multi-Generational Income Disadvantage and the Educational Attainment of Young Adults." Research in Social Stratification and Mobility 35:53-69.

Zeng, Zhen, and Yu Xie. 2014. "The Effects of Grandparents on Children's Schooling: Evidence from Rural China." Demography 51(2):599-617. 


\section{ENDNOTES}

${ }^{1}$ The model includes direct links between grandparents' education and each construct, each of which is directly linked to children's education. Each construct may also affect any subsequent construct, although I have omitted some of the arrows to reduce clutter; I symbolize these omitted arrows with gray double-lined arrows.

${ }^{2}$ This does not mean that educational attainment is measured at age 25 ; it is measured at the oldest available age beyond the cutoff. I may not capture the completed education of adults who pursue further schooling in the future, but my age cutoffs should at least capture those who complete their education “on-time," which has additional benefits (Elman and O'Rand 2004).

${ }^{3}$ I conducted parallel analyses using non-parametric methods and obtained similar results. These methods do not model the outcome and thus avoid functional form assumptions; instead they use inverse probability weighting to balance covariate distributions across groups and assess how much between-group inequality the covariate balancing explains. I do not report these analyses for simplicity and because they yield imprecise estimates.

${ }^{4}$ I estimate standard errors using seemingly unrelated estimation in Stata to appropriately account for dependence in the estimates across models.

${ }^{5}$ This is because using the low group as a reference entails worsening the higher groups' attributes (covariate means); using the high group as a reference entails improving the lower groups' attributes. Changes in attribute levels are the same regardless of the reference group, so differences in components capture differences in effects. Hence, if the covariates have stronger effects in the high group, they will explain more inequality with the low group reference, and vice versa. 


\section{FIGURE LEGEND}

Figure 1. Conceptual Model. A: antecedent attributes, E: education, F: family upbringing, S: skills and personal attributes, and O: educational orientations; $g$, $p$, and c index grandparents, parents, and children, respectively. Double-lined gray arrows indicate that construct may affect any subsequent construct.

*Attached as a power point file

Figure 2. Direct Effects and Parent Controls. Bars indicate multigenerational gaps in the highest grade of completed school for the high-middle, middle-low, and high-low group comparisons. For each comparison, the first cluster is based on analyses using both parents' education as parent attainment measures; the second adds parents' income and wealth. Each cluster includes the raw gap (white), the residual gap after controlling for parent attainment (black), and the residual gap after controlling for additional parent attributes (gray). Bars with diagonal pattern include interactions between grandparents' education and all covariates.

*Attached with data as an excel file

Figure 3. Sequential Decompositions, All Outcomes. Each line shows the percentage of the raw gap remaining at each stage in the sequence. Estimates for high school diploma, college attendance, and bachelor's degree attainment are based on predicted probabilities after logistic regressions. All covariates are interacted with grandparent education; estimates are based on predictions at middle-group covariate means. X-axis labels correspond to constructs (see text, Table 1).

*Attached with data as an excel file 


\section{TABLES}

Table 1. Descriptive Statistics by Grandparent Education

\begin{tabular}{|c|c|c|c|c|c|c|c|c|c|}
\hline & \multicolumn{3}{|c|}{$\begin{array}{c}\text { Low } \\
(<\mathrm{HS}) \\
\mathrm{N}=2,012\end{array}$} & \multicolumn{3}{|c|}{$\begin{array}{c}\text { Mid } \\
\text { (HS, some college) } \\
\mathrm{N}=1,904 \\
\end{array}$} & \multicolumn{3}{|c|}{$\begin{array}{c}\text { High } \\
\text { (Bachelor's degree) } \\
\mathrm{N}=285 \\
\end{array}$} \\
\hline & Obs & Mean & SD & Obs & Mean & SD & Obs & Mean & SD \\
\hline \multicolumn{10}{|l|}{ Ag: Antecedents and controls } \\
\hline Female & 2,012 & 0.50 & 0.50 & 1,904 & 0.51 & 0.50 & 285 & 0.49 & 0.50 \\
\hline Black & 2,012 & 0.42 & 0.49 & 1,904 & 0.36 & 0.48 & 285 & 0.20 & 0.40 \\
\hline Hispanic & 2,012 & 0.35 & 0.48 & 1,904 & 0.12 & 0.32 & 285 & 0.11 & 0.32 \\
\hline Grandparent immigrant & 2,012 & 0.18 & 0.38 & 1,904 & 0.07 & 0.25 & 285 & 0.12 & 0.32 \\
\hline \multicolumn{10}{|l|}{$F_{p}:$ Mother's family upbringing } \\
\hline Home reading scale & 1,987 & -0.41 & 0.76 & 1,890 & 0.14 & 0.66 & 284 & 0.48 & 0.48 \\
\hline 2-parent biological, 0-18 & 1,928 & 0.48 & 0.50 & 1,836 & 0.53 & 0.50 & 275 & 0.68 & 0.47 \\
\hline Sibship size & 2,006 & 5.59 & 3.20 & 1,901 & 3.70 & 2.36 & 285 & 3.39 & 2.03 \\
\hline \multicolumn{10}{|l|}{$S_{p}:$ Mother's skills and attributes } \\
\hline AFQT percentile & 1,933 & 20.25 & 18.35 & 1,818 & 37.20 & 26.02 & 271 & 60.45 & 26.05 \\
\hline Delinquency scale & 1,832 & -0.06 & 0.67 & 1,735 & 0.02 & 0.67 & 261 & 0.02 & 0.86 \\
\hline Locus of control & 1,988 & 9.43 & 2.26 & 1,892 & 8.85 & 2.43 & 283 & 7.85 & 2.54 \\
\hline \multicolumn{10}{|c|}{$O_{p}:$ Mother's educational orientation } \\
\hline Educational aspirations & 1,996 & 13.25 & 2.31 & 1,896 & 14.11 & 2.11 & 281 & 15.58 & 1.85 \\
\hline Educational expectations & 1,985 & 12.40 & 2.37 & 1,885 & 13.46 & 2.08 & 284 & 15.14 & 1.94 \\
\hline \multicolumn{10}{|l|}{ E1 $:$ Parents' education } \\
\hline Mother: No HS diploma & 1,927 & 0.39 & 0.49 & 1,850 & 0.18 & 0.38 & 283 & 0.05 & 0.22 \\
\hline Mother: HS diploma & 1,927 & 0.30 & 0.46 & 1,850 & 0.35 & 0.48 & 283 & 0.15 & 0.36 \\
\hline Mother: Some college & 1,927 & 0.24 & 0.43 & 1,850 & 0.32 & 0.47 & 283 & 0.39 & 0.49 \\
\hline Mother: Bachelor's degree & 1,927 & 0.05 & 0.21 & 1,850 & 0.10 & 0.29 & 283 & 0.27 & 0.44 \\
\hline Mother: Graduate degree & 1,927 & 0.02 & 0.14 & 1,850 & 0.05 & 0.23 & 283 & 0.15 & 0.36 \\
\hline Father: No HS diploma & 1,879 & 0.28 & 0.45 & 1,819 & 0.11 & 0.31 & 283 & 0.07 & 0.25 \\
\hline Father: HS diploma & 1,879 & 0.50 & 0.50 & 1,819 & 0.52 & 0.50 & 283 & 0.35 & 0.48 \\
\hline Father: Some college & 1,879 & 0.15 & 0.36 & 1,819 & 0.23 & 0.42 & 283 & 0.23 & 0.42 \\
\hline
\end{tabular}




\begin{tabular}{|c|c|c|c|c|c|c|c|c|c|}
\hline Father: Bachelor's degree & 1,879 & 0.06 & 0.23 & 1,819 & 0.09 & 0.29 & 283 & 0.24 & 0.43 \\
\hline Father: Graduate degree & 1,879 & 0.02 & 0.13 & 1,819 & 0.04 & 0.21 & 283 & 0.12 & 0.33 \\
\hline Avg. schooling, aunts/uncles & 1,904 & 10.96 & 2.17 & 1,792 & 12.36 & 1.85 & 276 & 14.13 & 2.38 \\
\hline \multicolumn{10}{|l|}{$E 2_{p}:$ Parents' economic attainment } \\
\hline Log avg. family income & 2,011 & 9.77 & 0.67 & 1,901 & 10.17 & 0.69 & 284 & 10.58 & 0.64 \\
\hline Avg. net worth $(\$ 1,000 s)$ & 2,009 & 21.87 & 54.69 & 1,904 & 52.12 & 103.77 & 284 & 103.94 & 143.02 \\
\hline \multicolumn{10}{|l|}{$F_{c}:$ Children's family upbringing } \\
\hline Grandparent coresidence $\left(\mathrm{F} 1_{\mathrm{c}}\right)$ & 2,010 & 0.39 & 0.49 & 1,904 & 0.31 & 0.46 & 285 & 0.24 & 0.43 \\
\hline Mother's age at birth & 2,012 & 20.92 & 3.35 & 1,904 & 21.65 & 3.31 & 285 & 23.07 & 3.22 \\
\hline Sibship size & 2,012 & 2.25 & 1.45 & 1,904 & 1.87 & 1.25 & 285 & 1.72 & 1.07 \\
\hline 2-parent biological w/ disruption & 2,012 & 0.55 & 0.50 & 1,904 & 0.55 & 0.50 & 285 & 0.48 & 0.50 \\
\hline 2-parent biological never & 2,012 & 0.30 & 0.46 & 1,904 & 0.24 & 0.43 & 285 & 0.17 & 0.37 \\
\hline Cognitive stimulation (HOME) & 1,991 & 93.00 & 12.57 & 1,879 & 99.98 & 11.31 & 283 & 106.31 & 9.31 \\
\hline Emotional support (HOME) & 1,986 & 94.74 & 12.05 & 1,877 & 99.10 & 11.00 & 283 & 103.06 & 10.42 \\
\hline \multicolumn{10}{|l|}{$S_{c}:$ Children's skills and attributes } \\
\hline Behavior problems & 1,853 & 0.20 & 0.85 & 1,790 & 0.13 & 0.84 & 274 & 0.02 & .81 \\
\hline Intellectual skills & 1,814 & -0.37 & 0.84 & 1,709 & -0.02 & 0.80 & 266 & 0.44 & 0.80 \\
\hline Self-perceived scholastic ability & 1,806 & -0.11 & 0.83 & 1,701 & 0.04 & 0.88 & 253 & 0.30 & 0.80 \\
\hline Delinquency & 1,872 & 0.10 & 0.70 & 1,738 & 0.02 & 0.63 & 267 & -0.06 & 0.53 \\
\hline Drug use & 1,903 & 0.10 & 0.74 & 1,779 & 0.13 & 0.82 & 269 & 0.09 & 0.64 \\
\hline \multicolumn{10}{|l|}{$O_{c}:$ Educational goals } \\
\hline Children's aspirations & 1,589 & 15.05 & 2.18 & 1,482 & 15.48 & 2.04 & 206 & 16.18 & 1.58 \\
\hline Children's expectations & 1,610 & 14.64 & 2.24 & 1,504 & 15.19 & 2.99 & 207 & 15.84 & 1.84 \\
\hline Parents' expectations & 1,873 & 14.39 & 1.95 & 1,787 & 14.98 & 1.74 & 270 & 15.91 & 1.40 \\
\hline \multicolumn{10}{|l|}{$E_{c}:$ Children's outcomes } \\
\hline Highest grade completed $(25+)$ & 2,012 & 12.67 & 2.17 & 1,904 & 13.39 & 2.28 & 285 & 14.80 & 2.43 \\
\hline High school completion & 1,844 & 0.67 & 0.47 & 1,692 & 0.78 & 0.42 & 241 & 0.88 & 0.32 \\
\hline College attendance & 2,003 & 0.54 & 0.50 & 1,888 & 0.65 & 0.48 & 284 & 0.85 & 0.36 \\
\hline Bachelor's degree & 2,012 & 0.17 & 0.38 & 1,904 & 0.27 & 0.44 & 285 & 0.49 & 0.50 \\
\hline
\end{tabular}

Note: restricted to cases with complete data for grandparents' education and highest grade completed. 
Table 2. Sequential Decomposition: Highest Grade Completed

\begin{tabular}{|c|c|c|c|c|c|c|c|c|c|}
\hline & \multicolumn{3}{|c|}{ High vs. Mid } & \multicolumn{3}{|c|}{ Mid vs. Low } & \multicolumn{3}{|c|}{ High vs. Low } \\
\hline & Comp. & SE & $\%$ & Comp. & $\mathrm{SE}$ & $\%$ & Comp. & $\mathrm{SE}$ & $\%$ \\
\hline Raw gap & $1.41^{*}$ & $(0.19)$ & -- & $0.72 *$ & $(0.09)$ & -- & $2.13^{*}$ & $(0.19)$ & -- \\
\hline Antecedents/controls & $0.22 *$ & $(0.09)$ & 15.3 & 0.08 & $(0.05)$ & 11.1 & $0.30 *$ & $(0.10)$ & 13.9 \\
\hline \multicolumn{10}{|l|}{ Parent Traits (indirect) } \\
\hline Family upbringing & $0.23 *$ & $(0.12)$ & 16.5 & $0.25 *$ & $(0.04)$ & 35.3 & $0.49 *$ & $(0.12)$ & 22.8 \\
\hline Skills & $0.52 *$ & $(0.15)$ & 36.9 & $0.32 *$ & $(0.06)$ & 44.7 & $0.84^{*}$ & $(0.15)$ & 39.5 \\
\hline Educ. Orientations & $0.27 *$ & $(0.11)$ & 19.2 & 0.03 & $(0.02)$ & 3.7 & $0.30 *$ & $(0.11)$ & 14.0 \\
\hline Education & 0.07 & $(0.08)$ & 5.2 & $0.11 *$ & $(0.04)$ & 15.8 & $0.19 *$ & $(0.09)$ & 8.7 \\
\hline Economic attainment & -0.02 & $(0.06)$ & -1.3 & $0.08 *$ & $(0.03)$ & 10.7 & 0.06 & $(0.06)$ & 2.7 \\
\hline \multicolumn{10}{|l|}{ Child Traits (direct) } \\
\hline GP coresidence & 0.00 & $(0.01)$ & -0.2 & 0.01 & $(0.01)$ & 0.9 & 0.00 & $(0.01)$ & 0.2 \\
\hline Family upbringing & 0.13 & $(0.09)$ & 9.5 & -0.02 & $(0.02)$ & -2.6 & 0.12 & $(0.09)$ & 5.5 \\
\hline Skills & -0.04 & $(0.10)$ & -2.8 & -0.05 & $(0.03)$ & -7.0 & -0.09 & $(0.10)$ & -4.2 \\
\hline Educ. Orientations & 0.08 & $(0.09)$ & 5.4 & 0.02 & $(0.02)$ & 2.8 & 0.10 & $(0.09)$ & 4.5 \\
\hline Unexplained & -0.05 & $(0.18)$ & -3.6 & -0.11 & $(0.08)$ & -15.4 & -0.16 & $(0.19)$ & -7.5 \\
\hline
\end{tabular}


Table 3. Summary of Sequential Decompositions for All Outcomes

\begin{tabular}{|c|c|c|c|c|c|c|c|c|c|c|c|c|}
\hline & \multicolumn{3}{|c|}{$\begin{array}{l}\text { Highest Grade } \\
\text { (OLS) }\end{array}$} & \multicolumn{3}{|c|}{$\begin{array}{c}\text { HS Diploma } \\
\text { (Logit) } \\
\mathrm{N}=3,753\end{array}$} & \multicolumn{3}{|c|}{$\begin{array}{c}\begin{array}{c}\text { College Attendance } \\
\text { (Logit) }\end{array} \\
\mathrm{N}=3,753\end{array}$} & \multicolumn{3}{|c|}{$\begin{array}{c}\begin{array}{c}\text { Bachelor's Degree } \\
\text { (Logit) }\end{array} \\
\mathrm{N}=3,753\end{array}$} \\
\hline & $\mathrm{H}-\mathrm{M}$ & M-L & H-L & H-M & M-L & H-L & H-M & M-L & H-L & H-M & M-L & $\mathrm{H}-\mathrm{L}$ \\
\hline Raw Gap ${ }^{a}$ & 1.50 & 0.69 & 2.19 & 0.11 & 0.11 & 0.22 & 0.21 & 0.11 & 0.32 & 0.24 & 0.09 & 0.32 \\
\hline Antecedents/controls & 15.6 & 14.0 & 15.1 & 5.6 & 10.7 & 8.2 & 3.4 & -6.0 & 0.2 & 17.5 & 6.5 & 14.5 \\
\hline Parent attributes (indirect) & 73.1 & 111.7 & 85.2 & 52.0 & 78.7 & 65.5 & 33.6 & 133.3 & 67.7 & 77.4 & 114.9 & 87.5 \\
\hline Family upbringing & 20.8 & 37.2 & 26.0 & 28.3 & 36.2 & 32.3 & 15.5 & 39.6 & 23.8 & 15.1 & 32.6 & 19.9 \\
\hline Skills & 37.2 & 40.9 & 38.3 & 19.1 & 34.2 & 26.7 & 22.7 & 52.0 & 32.7 & 36.9 & 41.1 & 38.0 \\
\hline Educ. orientations & 14.3 & 4.1 & 11.1 & -24.4 & 2.1 & -11.0 & 7.1 & 4.2 & 6.1 & 17.3 & 7.9 & 14.7 \\
\hline Education & 3.6 & 18.3 & 8.2 & 21.7 & 4.4 & 12.9 & -1.4 & 19.3 & 5.7 & 7.7 & 21.8 & 11.5 \\
\hline Economic attainment & -2.8 & 11.2 & 1.6 & 7.3 & 2.0 & 4.6 & -10.4 & 18.1 & -0.7 & 0.4 & 11.4 & 3.4 \\
\hline Child attributes (direct) & 11.4 & -3.4 & 6.7 & -28.6 & -3.8 & -16.0 & -31.9 & -1.1 & -21.4 & 37.5 & -5.0 & 25.9 \\
\hline GP coresidence & -0.4 & 1.0 & 0.1 & -0.7 & 0.9 & 0.1 & 0.0 & 0.3 & 0.1 & -0.5 & 0.8 & -0.2 \\
\hline Family upbringing & 11.0 & -3.1 & 6.6 & -11.0 & -4.2 & -7.6 & 7.0 & -3.1 & 3.5 & 11.6 & -3.1 & 7.6 \\
\hline Skills & -2.7 & -5.7 & -3.6 & -8.6 & -6.9 & -7.7 & -18.1 & -7.3 & -14.4 & 1.6 & 1.2 & 1.5 \\
\hline Educ. orientations & 3.4 & 4.4 & 3.7 & -8.3 & 6.4 & -0.9 & -20.8 & 9.0 & -10.6 & 24.9 & -3.9 & 17.0 \\
\hline Unexplained & 0.0 & -22.3 & -7.0 & 70.9 & 14.4 & 42.3 & 94.9 & -26.1 & 53.5 & -32.4 & -16.3 & -28.0 \\
\hline
\end{tabular}




\section{APPENDIX}

Table A1. Description of Scale Construction

\begin{tabular}{|c|c|c|c|c|c|}
\hline Construct/variable & Items & Ages & Reporter & $\begin{array}{l}\text { Mean, } \\
\text { SD }\end{array}$ & $\begin{array}{l}\text { Scale } \\
\text { Reliability }\end{array}$ \\
\hline \multicolumn{6}{|l|}{ Parents' Upbringing } \\
\hline Home reading & $\begin{array}{l}3 \text { items: magazines, newspapers, library card } \\
\text { in home }\end{array}$ & 14 & Mother & 0,1 & 0.73 \\
\hline \multicolumn{6}{|l|}{ Parents' Traits } \\
\hline Delinquency & 17 delinquency/drug use items & $15-22(1980)$ & Mother & 0,1 & 0.92 \\
\hline \multicolumn{6}{|l|}{ Children's Traits } \\
\hline \multirow[t]{3}{*}{ Intellectual skills } & PIAT math, PIAT reading recognition, PIAT & $9-10$ & Assessed & 0,1 & 0.85 \\
\hline & reading comprehension, Memory for digit & $11-12$ & Assessed & 0,1 & 0.84 \\
\hline & span (9-10 and $11-12$ only) & $13-14$ & Assessed & 0,1 & 0.81 \\
\hline \multirow[t]{3}{*}{ Behavior problems } & 6 BPI subscales: conflict, hyperactive, & $9-10$ & Mother & 0,1 & 0.85 \\
\hline & headstrong, dependent, anxiety/depression, & $11-12$ & Mother & 0,1 & 0.85 \\
\hline & antisocial & $13-14$ & Mother & 0,1 & 0.84 \\
\hline \multirow[t]{5}{*}{ Delinquency } & 9 delinquency items: break curfew, hurt & $9-10$ & Child & 0,1 & 0.93 \\
\hline & others, lie to parents, steal, damage school & $11-12$ & Child & 0,1 & 0.91 \\
\hline & property, got drunk, trouble at school, skip & $13-14$ & Child & 0,1 & 0.89 \\
\hline & school, out w/o permission & $15-16$ & Child & 0,1 & 0.88 \\
\hline & & $17-18$ & Child & 0,1 & 0.85 \\
\hline \multirow[t]{5}{*}{ Drug use } & 4 drug use items: smoked recently, drank & $9-10$ & Child & 0,1 & 0.91 \\
\hline & alcohol recently, smoked marijuana recently, & $11-12$ & Child & 0,1 & 0.93 \\
\hline & used other drugs recently & $13-14$ & Child & 0,1 & 0.92 \\
\hline & & $15-16$ & Child & 0,1 & 0.92 \\
\hline & & $17-18$ & Child & 0,1 & 0.90 \\
\hline
\end{tabular}

${ }^{a}$ Scale reliability is based on maximal reliability derived from factor analyses. Factor analyses for delinquency and drug use use polychoric correlation matrices to incorporate categorical responses. Each age grouping includes the measures collected when the child was in that age range, roughly corresponding to one wave of data collection. 
Table A2. Selected Interactions: Highest Grade Completed, Coefficients by Grandparent Education

\begin{tabular}{|c|c|c|c|c|c|c|c|c|}
\hline & \multicolumn{4}{|c|}{ First Model } & \multicolumn{4}{|c|}{ Final Model } \\
\hline & Low & Middle & High & Diffs & Low & Middle & High & Diffs \\
\hline \multicolumn{9}{|l|}{ Antecedents } \\
\hline Black & -0.25 & -0.50 & -1.39 & $\mathrm{HL}^{*}, \mathrm{HM}^{*}$ & 0.21 & 0.20 & -0.66 & $\mathrm{HL}^{*}, \mathrm{HM}^{*}$ \\
\hline Hispanic & -0.65 & -0.63 & -2.18 & $\mathrm{HL}^{*}, \mathrm{HM}^{*}$ & -0.09 & -0.04 & -1.13 & $\mathrm{HL}^{*}, \mathrm{HM}^{*}$ \\
\hline GP immigrant & 0.76 & 0.24 & -0.12 & $\mathrm{HL} \dagger$ & 0.58 & -0.04 & -0.32 & $\mathrm{HL}^{*}, \mathrm{ML}^{*}$ \\
\hline \multicolumn{9}{|l|}{ Mothers' skills and attributes } \\
\hline Delinquency & -0.12 & -0.20 & 0.17 & $\mathrm{HM} \dagger$ & 0.00 & 0.00 & 0.35 & $\mathrm{HL}^{*}, \mathrm{HM}^{*}$ \\
\hline \multicolumn{9}{|l|}{ Parents' economic attainment } \\
\hline Avg. net worth $(\$ 10,000 \mathrm{~s})$ & 0.04 & 0.02 & 0.02 & $\mathrm{HL} \uparrow, \mathrm{ML}^{*}$ & 0.03 & 0.01 & 0.01 & $\mathrm{HL} \dagger, \mathrm{ML} \dagger$ \\
\hline \multicolumn{9}{|l|}{ Children's family upbringing } \\
\hline Cognitive stimulation & 0.02 & 0.03 & 0.07 & $\mathrm{HL}^{*}, \mathrm{HM}^{*}$ & 0.00 & 0.01 & 0.04 & $\mathrm{HL}^{*}, \mathrm{HM}^{*}$ \\
\hline \multicolumn{9}{|c|}{ Children's educational orientations } \\
\hline Educational expectations & 0.17 & 0.05 & 0.33 & $\mathrm{HM}^{*}, \mathrm{ML}^{*}$ & 0.17 & 0.05 & 0.33 & $\mathrm{HM}^{*}, \mathrm{ML}^{*}$ \\
\hline
\end{tabular}

Diffs column indicates which groups' coefficients are statistically significantly different $\left({ }^{*} p<.05, p<.10\right)$. First Model is the first in the sequence in which the variables were introduced; final model is the full model with all covariates. 
Table A3. Decompositions with Different Reference Groups: Highest Grade Completed

\begin{tabular}{|c|c|c|c|c|c|c|c|c|c|c|c|c|}
\hline & \multicolumn{3}{|c|}{ No Interactions } & \multicolumn{3}{|c|}{ "Middle Reference } & \multicolumn{3}{|c|}{ Low Reference } & \multicolumn{3}{|c|}{ High Reference } \\
\hline & $\mathrm{H}-\mathrm{M}$ & M-L & $\mathrm{H}-\mathrm{L}$ & H-M & M-L & $\mathrm{H}-\mathrm{L}$ & $\mathrm{H}-\mathrm{M}$ & M-L & $\mathrm{H}-\mathrm{L}$ & $\mathrm{H}-\mathrm{M}$ & M-L & $\mathrm{H}-\mathrm{L}$ \\
\hline Antecedents & 6.8 & 20.1 & 11.3 & 15.3 & 11.1 & 13.9 & 46.7 & 20.6 & 37.9 & 6.0 & 9.2 & 7.1 \\
\hline Parent attributes & 71.9 & 97.5 & 80.5 & 76.3 & 110.1 & 87.7 & 81.2 & 96.7 & 86.4 & 65.0 & 152.1 & 94.3 \\
\hline Child attributes & 3.4 & -3.5 & 1.1 & 12.0 & -5.9 & 6.0 & 23.1 & -10.4 & 11.8 & 7.1 & -31.4 & -5.8 \\
\hline Unexplained & 17.9 & -14.1 & 7.1 & -3.6 & -15.4 & -7.5 & -51.0 & -6.8 & -36.1 & 21.9 & -29.9 & 4.5 \\
\hline
\end{tabular}

Each cell contains \% attributed to each component. For analyses with interactions, covariates are held at the means of the reference group; this is the reduction in multigenerational inequality after equating other groups' attributes with those of the reference group. 